\title{
Lansoprazole Raises Somatostatin, Calcitonin Gene-Related Peptide, and Substance P Levels in Healthy Human Plasma
}

\author{
Fumihiko Katagiri,* Shin Inoue, Yuhki Sato, Hiroki Itoh, and Masaharu Takeyama \\ Department of Clinical Pharmacy, Oita University Hospital, 1-1, Idaigaoka, Hasama-machi, Oita 879-5593, Japan
}

(Received November 25, 2004; Accepted January 17, 2005)

\begin{abstract}
Lansoprazole, a proton pump inhibitor (PPI), is widely used in the treatment of peptic ulcer, gastroesophageal reflux disease and eradication of Helicobacter pylori. Lansoprazole has been reported to be a PPI with mucosal protective action. However, except for inhibition of gastric acid secretion, its mechanism of action is not well understood. We therefore examined the effects of lansoprazole on plasma levels of gastrointestinal peptides (gastrin, somatostatin, motilin, vasoactive intestinal peptide [VIP], substance P, and calcitonin gene-related peptide [CGRP]). Lansoprazole $30 \mathrm{mg}$ or placebo was orally administered to five healthy male volunteers aged 25-30 years. Venous blood samples were taken before and 30, 60, 90, 120, 180, 240, and 360 min after administration. Plasma peptide levels were measured using a sensitive enzyme immunoassay. Compared with the response of the placebo treated group, lansoprazole caused significant $(p<0.05)$ increases in somatostatin-, VIP-, substance P- and CGRP-like immunoreactive substance (IS) levels at 120, 120, 90-240, and $120 \mathrm{~min}$, respectively. Furthermore, lansoprazole significantly suppressed temporary elevation $(30 \mathrm{~min}$ ) of placebo gastrin-IS levels. But lansoprazole had no effect on plasma motilin-IS levels compared with the placebo. In this study, lansoprazole raised somatostatin-IS levels and inhibited the increase in gastrin-IS levels. On the other hand, lansoprazole raised substance P- and CGRP-IS levels. Recently, capsaicin-sensitive afferent nerves have been shown to play an important role in gastric mucosal defensive mechanisms. Capsaicin stimulates afferent nerves and enhances the release of CGRP and substance P in the stomach. We hypothesize that lansoprazole might not only potently inhibit gastric acid secretion but also exert gastroprotective actions via capsaicin-sensitive afferent nerves.
\end{abstract}

Key words — lansoprazole, gastroprotective effect, calcitonin gene-related peptide, substance P

\section{INTRODUCTION}

$\left(\mathrm{H}^{+} / \mathrm{K}^{+}\right)$-ATPase, localized on gastric mucosal cells, plays an important role in gastric acid secretion as a proton pump. Because $\left(\mathrm{H}^{+} / \mathrm{K}^{+}\right)$-ATPase is located in the final stage of the gastric acid secretion mechanism, proton pump inhibitors (PPIs) that inhibit $\left(\mathrm{H}^{+} / \mathrm{K}^{+}\right)$-ATPase are considered to inhibit acid secretion to any desired level.

Lansoprazole was introduced in 1984 as a PPI with a pyridine ring, conferring potent inhibition of gastric acid secretion, and a benzimidazole structure, which has antiulcer activity and antiallergy activity. Today, lansoprazole is widely used in the treatment of peptic ulcer, gastroesophageal reflux

*To whom correspondence should be addressed: Department of Clinical Pharmacy, Oita University Hospital, 1-1, Idaigaoka, Hasama-machi, Oita 879-5593, Japan. Tel.: +81-97-586-6113; Fax: +81-97-586-6119; E-mail: FKATA@med.oita-u.ac.jp disease, and eradication of Helicobacter pylori together with amoxicillin and clarithromycin.

PPIs not only have potent gastric antisecretory but also mucosal protective actions. Lansoprazole also has mucosal protective activity, ${ }^{1,2)}$ although mechanism of action except for the inhibition of gastric acid secretion ${ }^{1,3)}$ is not well understood.

One of the gastrointestinal motility regulatory factors in those empirical effects has been assumed to be the induction of changes in the levels of peptides (gastrin, somatotatin, vasoactive intestinal peptide [VIP] and motilin) in plasma. In the gastroprotective function as a neural emergency system, sensory afferent neurons in the gastrointestinal mucosa regulate neuropeptide (calcitonin gene-related peptide [CGRP] and tachykinins [substance P, etc.]) levels and play various physiologic roles. $\left.{ }^{4}\right)$

The purpose of this study was to determine the effects of lansoprazole on plasma levels of gut-regulatory peptides (gastrin-, somatostatin-, motilin- and 
VIP-like immunoreactive substance [IS]) and how the gastrointestinal mucosa regulates neuropeptides (substance P- and CGRP-IS) in healthy volunteers.

\section{MATERIALS AND METHODS}

Materials _ Lansoprazole was used in the form of Takepron OD tablets (Takeda Chemical Industries, Ltd., Osaka, Japan). Lactose (Merck Hoei Co., Ltd., Osaka, Japan) was used as a placebo.

Synthetic human gastrin I (G17), somatostatin, motilin, VIP, human CGRP and its fragment (8-37), and substance $\mathrm{P}$ were purchased from the Peptide Institute (Osaka, Japan). Fragment gastrin I (2-17) was purchased from Sigma Chemicals (St. Louis, MO, U.S.A.) Motilin and VIP fragment peptide were supplied by Professor H. Yajima. (Kyoto University, Kyoto, Japan). Antisera to gastrin (A600/R1B) and VIP (A604/R1B) were purchased from Biogenesis (Poole, U.K.), CGRP (CA1132) was purchased from Affiniti Research Products Ltd. (Nottingham, U.K.), somatostatin (RA-08-108) and substance P (RA-08095) from Cambridge Research Biochemicals (Cambridge, U.K.), and motilin (Y121) from Yanaihara Institute (Shizuoka, Japan). All other reagents were of analytical reagent grade from commercial sources. Volunteers — Five healthy male volunteers, aged 25-30 years (median 27 years), weighing 55-68 kg (median $63 \mathrm{~kg}$ ), participated in the study. Each received information on the scientific purpose of the study and gave written informed consent for participation. The study protocol was approved by the Ethical Committee of Oita Medical University. The subjects did not receive any medication 1 week before the study, and fasted for $3 \mathrm{hr}$ before the study commenced and during the experiments.

Study Schedule —_Lansoprazole (30 mg) or placebo was administered orally with $100 \mathrm{ml}$ of water. They were administered at an interval of 4 weeks. The subjects did not take other drugs for 1 week before this study. The dose of lansoprazole in this study was the maximum daily dose in clinical therapy. Venous blood samples $(10 \mathrm{ml})$ were taken from a forearm vein before and at 30, 60, 90, 120, 180, 240, and 360 min after administration. The study was carried out from 11:30 to 17:30.

Determination of Lansoprazole Levels in Plasma

The plasma concentration of lansoprazole was determined using the modified method of Aoki and Yashiki. ${ }^{5)}$ Plasma samples $(1 \mathrm{ml})$ were extracted twice with $6 \mathrm{ml}$ of diethylether-dichloromethane
$(7: 3, v / v)$. After centrifugation $(2500 \mathrm{~g}, 10 \mathrm{~min})$, $1 \mathrm{ml}$ of propylene glycol solution (propylene glycol-diethylether-dichloromethane, $1: 140: 60$ ) was added to the supernatant, and the solvent was evaporated. The residue was dissolved in $1 \mathrm{ml}$ of mobile phase, and $200 \mu$ lof the solution was subjected to HPLC. HPLC was carried out using a C18 column (Cosmosil 5C18-AR; Nacalai Tesque, Kyoto, Japan) with UV detection at $285 \mathrm{~nm}$, and water-acetonitrile- $n$-octylamine $(620: 380: 1)$ was used as a mobile phase at a flow rate of $1.0 \mathrm{ml} / \mathrm{min}$.

Enzyme Immunoassay (EIA) of Gastrin, Somatostatin, Motilin, VIP, CGRP, and Substance P

The blood samples were placed in chilled tubes containing 500-kallikrein inhibitor units $/ \mathrm{ml}$ of aprotinin and $1.2 \mathrm{mg} / \mathrm{ml}$ of EDTA. After centrifugation, plasma samples were diluted five-fold with $4 \%$ acetic acid ( $\mathrm{pH} 4.0)$ and loaded onto $\mathrm{C} 18$ reversephase cartridges (Sep-Pak C18; Millipore Corp., Milford, MA, U.S.A.). After washing with $4 \%$ acetic acid, plasma peptides were eluted with $70 \%$ acetonitrile in $0.5 \%$ acetic acid ( $\mathrm{pH} 4.0)$. Eluates were concentrated by spin-vacuum evaporation, lyophilized, and stored at $-40^{\circ} \mathrm{C}$ until assayed. The recovery of plasma gastrin-, somatostatin-, motilin-, VIP-, CGRP- and substance P-IS was > $90 \%$ with this extracting procedure (data not shown).

Enzyme immunoassays (EIAs) for gastrin-, ${ }^{6}$ somatostatin- ${ }^{7)}$ motilin- ${ }^{8)}$ VIP-,${ }^{9}$ CGRP-, ${ }^{10)}$ and substance P-IS ${ }^{11)}$ were performed as previously described. The assays were performed using a delayed addition method. Separation of bound and free antigen was performed on an anti-rabbit IgG (55641, ICN Pharmaceuticals, Inc., Ohio, U.S.A.)-coated immunoplate (Nunc-Immuno Module Maxisorp F8, InterMed, Denmark). The fluorescent product 4methylumbelliferon was measured with an MTP100F microplate reader (Corona Electric, Ibaraki, Japan). Gastrin I (2-17), human somatostatin, porcine motilin, fragment VIP (11-28), human CGRP (8-37), and substance $\mathrm{P}$ were conjugated with $\beta$-Dgalactosidase (Boehringer Mannheim, Germany) with $N$-( $\varepsilon$-maleimidocaproyloxy)-succimide according to the method of Kitagawa et al. ${ }^{12)}$ The EIA for gastrin, somatostatin, motilin, VIP, CGRP, and substance $\mathrm{P}$ was specific and highly sensitive to detection limits of $0.04,0.10,0.80,1.00,0.08$, and $0.40 \mathrm{fmol} /$ well, respectively.

Statistical Analysis — The area under the plasma concentration-time curve $\left(\mathrm{AUC}_{0-360 \mathrm{~min}}\right)$ was calculated using the trapezoidal method. Results are expressed as mean \pm S.D. Comparison of mean values 
was done using the Mann Whitney U-test and $p<0.05$ was considered to represent a statistically significant difference.

\section{RESULTS AND DISCUSSIONS}

The profiles of mean plasma lansoprazole concentrations against time after oral administration of $30 \mathrm{mg}$ of the drug are shown Fig. 1. Lansoprazole caused a significant increase in the somatostatin-IS levels at $120 \mathrm{~min}(14.9 \pm 3.0 \mathrm{pg} / \mathrm{ml})$, compared with the response of the placebo group $(8.5 \pm 3.4 \mathrm{pg} / \mathrm{ml})$ (Fig. 2a). Figure 2b shows plasma VIP-IS levels after the administration of lansoprazole. Lansoprazole significantly increased VIP-IS levels at $120 \mathrm{~min}$ $(13.0 \pm 2.2 \mathrm{pg} / \mathrm{ml})$ compared with the response of the placebo group $(8.4 \pm 1.5 \mathrm{pg} / \mathrm{ml})$. Plasma substance P-IS levels were significantly increased between $90-240 \mathrm{~min}(38.2 \pm 11.2 \mathrm{pg} / \mathrm{ml}$ at $90 \mathrm{~min}, 38.1$ $\pm 5.3 \mathrm{pg} / \mathrm{ml}$ at $120 \mathrm{~min}, 22.5 \pm 3.6 \mathrm{pg} / \mathrm{ml}$ at $180 \mathrm{~min}$, and $18.2 \pm 3.5 \mathrm{pg} / \mathrm{ml}$ at $240 \mathrm{~min}$ ) compared with placebo $(14.4 \pm 2.3 \mathrm{pg} / \mathrm{ml}$ at $90 \mathrm{~min}, 15.2 \pm 4.6 \mathrm{pg} / \mathrm{ml}$ at $120 \mathrm{~min}, 13.3 \pm 4.0 \mathrm{pg} / \mathrm{ml}$ at $180 \mathrm{~min}$, and $11.5 \pm$ $3.0 \mathrm{pg} / \mathrm{ml}$ at $240 \mathrm{~min}$ ) (Fig. 2c). At $120 \mathrm{~min}$, the plasma CGRP-IS levels $(37.5 \pm 7.5 \mathrm{pg} / \mathrm{ml})$ were significantly increased compared with the placebo group (23.2 $\pm 4.4 \mathrm{pg} / \mathrm{ml})$ (Fig. 2d). Gastrin-IS leveltime profiles are shown in Fig. 2e. A temporary elevation in plasma gastrin-IS levels by placebo was significantly inhibited by lansoprazole administration. However, the drug did not alter levels of motilin-IS (Fig. 2f).

Table 1 shows total amounts of gastrointestinal peptide release $\left(\mathrm{AUC}_{0-360 \mathrm{~min}}\right)$ after administration of lansoprazole or placebo. The administration of lansoprazole caused the $\mathrm{AUC}_{0-360 \text { min }}$ of motilin to decrease significantly and that of substance $P$ to increase significantly.

Somatostatin, a 14-amino acid residue polypeptide, inhibits the secretion of other hormones, including gastrin, insulin, and motilin. ${ }^{13)}$ In the gastrointestinal tract, gastric acid and pepsin secretion and gastric emptying are inhibited by somatostatin. ${ }^{14)}$

Gastrin, a 17-amino acid residue polypeptide, stimulates gastric acid secretion. This peptide is associated with a mechanism of gastrointestinal motility involving the cholinergic nervous system. ${ }^{15)} \mathrm{In}$ Fig. 2e, the temporary elevation of gastrin-IS levels with placebo might be caused by direct stimulation of gastric mucosa $\mathrm{G}$ cells. After administration of lansoprazole, the temporary elevation of gastrin-IS

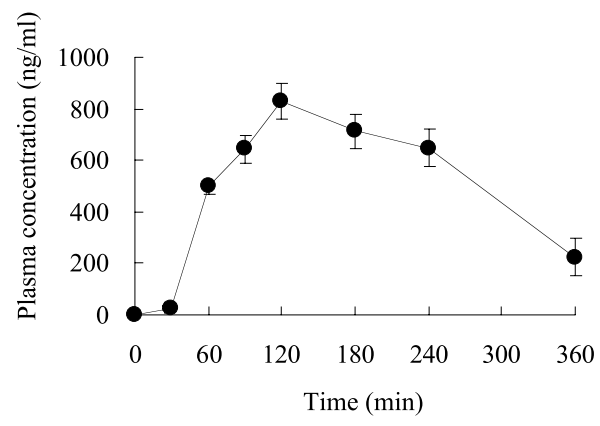

Fig. 1. Plasma Lansoprazole Levels after Oral Administration of $30 \mathrm{mg}$

Each value represents mean \pm S.D., $n=5$.

levels was inhibited. In this study, although somatostatin-IS levels reached peak concentrations at $120 \mathrm{~min}$ (Fig. 2a), gastrin-IS levels were not decreased compared with those in the placebo group but tended to increase $(p=0.08)$. Furthermore, before somatostatin-IS levels were increased, gastrinIS levels were inhibited. In this case, the changes in plasma gastrin-IS levels might not be due to the effects of somatostatin-IS. ${ }^{14,16)}$ We hypothesized that the increase in somatostatin might directly stimulate D cells, which secrete somatostatin-IS, and gastrin-IS might be inhibited until the drug concentration fell to $400 \mathrm{ng} / \mathrm{ml}$, i.e., time-dependent inhibition may occur. We assumed that the stimulation, which was instantaneous, did not have sufficient potency to change human homeostasis and only slightly influenced the total amount of these peptides. We also assumed that the gastrin-IS inhibition might not be due to direct action on G cells, but to indirect action. Therefore the total amount of gastrin-IS might not decrease significantly.

Motilin, a 22-amino acid residue polypeptide, has a powerful fundic pouch motor-stimulating activity. ${ }^{17)}$ It plays an important physiologic role in intestinal contractility and is one of the most important factors controlling the regular occurrence of phase- 3 contractions of the migrating motor complex (MMC) ${ }^{18,19)}$ In this study, motilin-IS levels did not change (Fig. 2f), but the total amount of motilin released $\left(\mathrm{AUC}_{0-360 \mathrm{~min}}\right)$ was significantly decreased to $91 \%$ compared with placebo (Table 1). Similar to gastrin-IS, it is not known whether the decrease in the amount of motilin released was due to somatostatin, but single administration of lansoprazole might cause gastric activity to decline.

VIP, a 28 -amino acid residue polypeptide, is widely distributed in the central and peripheral ner- 

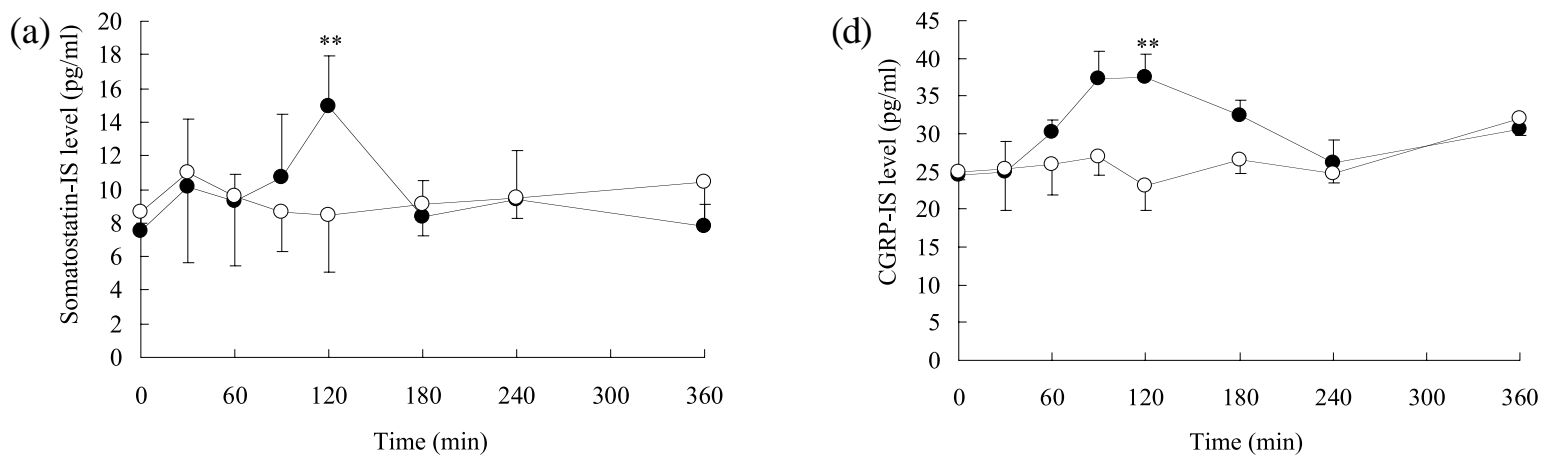

(b)
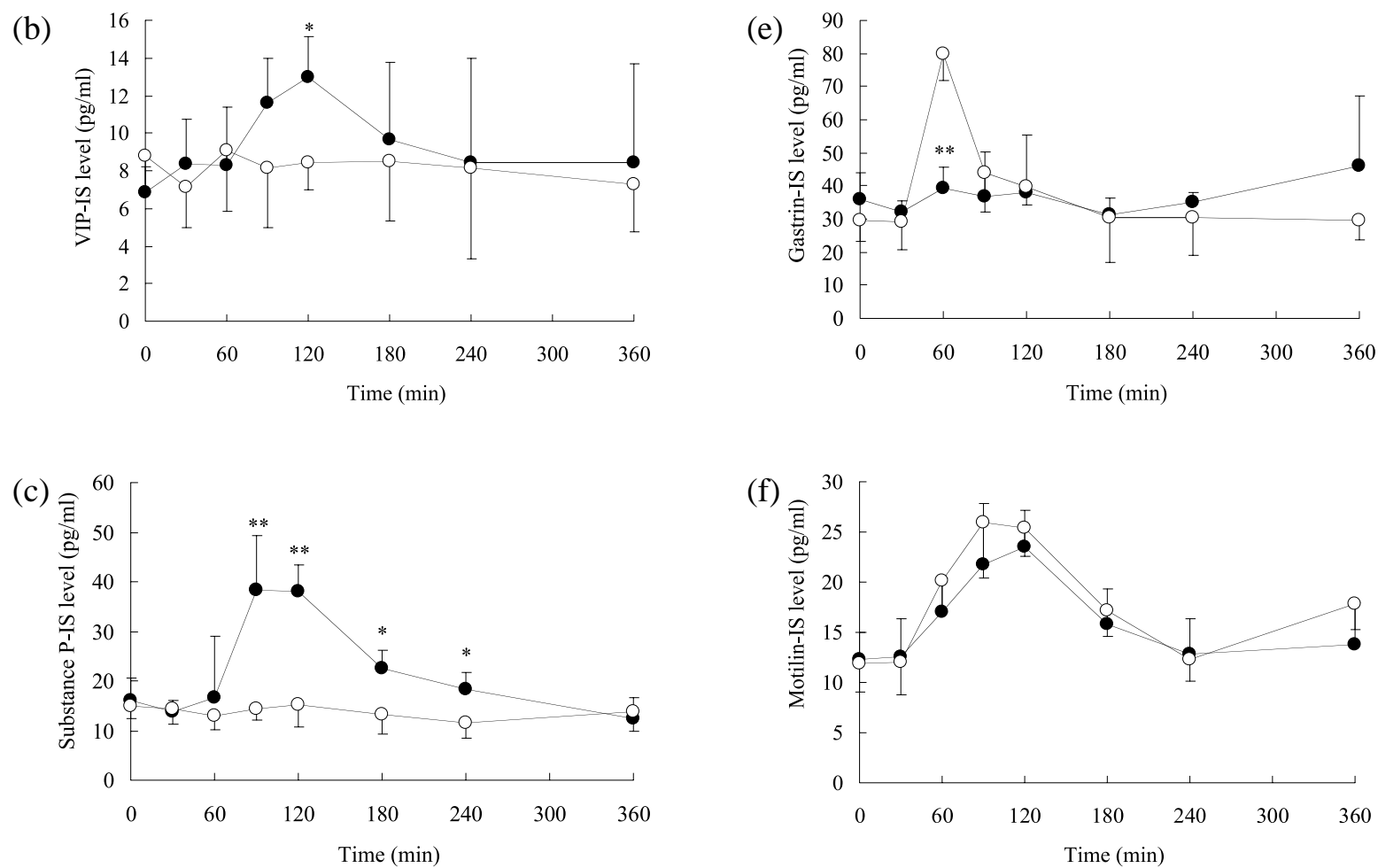

Fig. 2. Effects of Lansoprazole (๑) or Placebo $(\bigcirc)$ on Plasma Somatostatin (a), VIP (b), Substance P (c), CGRP (d), Gastrin (e) and Motilin (f) Levels

Each value represents mean \pm S.D., $n=5 . * p<0.05$ and $* * p<0.01$, significantly different compared with placebo.

Table 1. Total Amounts of Gastrointestinal Peptides Released (pg/ml·min) after Administration of Lansoprazole or Placebo

\begin{tabular}{lcc}
\hline \hline & Placebo & Lansoprazole \\
\hline Gastrin-IS & $13172.4 \pm 1535.1$ & $13285.6 \pm 1150.3$ \\
Somatostatin-IS & $3408.3 \pm 327.9$ & $3438.9 \pm 700.9$ \\
Motilin-IS & $6264.0 \pm 462.9$ & $5710.4 \pm 375.0^{*}$ \\
VIP-IS & $2922.0 \pm 262.3$ & $3374.3 \pm 1158.5$ \\
CGRP-IS & $9513.3 \pm 2564.1$ & $10961.5 \pm 1048.2$ \\
Substance P-IS & $4818.6 \pm 577.9$ & $7749.3 \pm 189.7 * *$ \\
\hline \multicolumn{2}{c}{ Each value represents mean \pm S.D., $n=5 .{ }^{*} p<0.05$ and ${ }^{* *} p<0.01$, signifi- } \\
cantly different compared with placebo.
\end{tabular}


vous system. ${ }^{20)}$ This peptide has vasodilating effects and increases blood flow, and Andersson et al. ${ }^{21)}$ suggested that VIP may be connected with vasodilation in the intestine. In addition, Angel et al. ${ }^{22)}$ reported that VIP may inhibit gastrointestinal motility. This information also supports our hypothesis; lansoprazole might cause gastric activity to decline. The effects of lansoprazole on plasma VIP-IS are not clear, and further investigation is needed.

CGRP is a powerful vasoactive substance, which is released from the sensory afferent nerve endings when gastric mucosal injury occurs in the stomach. CGRP increases gastric mucosal flow as a gastroprotective factor. ${ }^{4}$ Substance $P$ and other tachykinins, coexist with CGRP in the sensory afferent neurons of the gastrointestinal mucosa and are released with acetylcholine in response to depolarizing stimuli in the enteric nervous system. ${ }^{23)}$ In this study, lansoprazole raised plasma CGRP- and substance P-IS levels. Lansoprazole has been reported to have protective effects on the gastric mucosa. ${ }^{24,25)}$ There are reports that the drug might promote bicarbonate secretion, ${ }^{24)}$ or increase cyclooxygenase- 2 and prostaglandin (PG) $\mathrm{E}_{2}$ levels. ${ }^{25)}$ Recently, there have been many reports that capsaicin-sensitive afferent nerves are related to improved mucosal blood flow. Stimulation of the nervea causes the release of CGRP and substance $\mathrm{P}$ from nerve endings. Laftidine, a histamine $\mathrm{H}_{2}$ receptor antagonist, has a vanilloid structure, which is related to capsaicin, and alters the levels of CGRP and substance $P$ in human plasma. $\left.{ }^{26}\right)$ $\mathrm{PGE}_{2}$ also has cytoprotective effects via capsaicinsensitive afferent nerves. ${ }^{27)}$ Furthermore, Murakami et al. ${ }^{28)}$ reported that the gastric mucosal protective effects of lansoprazole are due to PGs and nitric oxide via an increase in mucosal blood flow. The results of this study supported the hypothesis that the protective effects of lansoprazole are caused by direct or indirect stimulation of capsaicin-sensitive afferent nerves.

In conclusion, lansoprazole potently inhibits gastric acid secretion, and we hypothesize that the drug causes a decrease in total gastric activity. In exerting gastroprotective effects, lansoprazole might increase mucosal blood flow via capsaicin-sensitive afferent nerves.

\section{REFERENCES}

1) Satoh, H., Inatomi, N., Nagaya, H., Inada, I., Nohara, A., Nakamura, N. and Maki, Y. (1989) Antisecretory and antiulcer activities of a novel proton pump inhibitor AG-1749 in dogs and rats. J. Pharmacol. Exp. Ther., 248, 806-815.

2) Inatomi, N., Nagaya, H., Takami, K., Shino, A. and Satoh, H. (1991) Effects of a proton pump inhibitor, AG-1749 (lansoprazole), on reflux esophagitis and experimental ulcers in rats. Jpn. J. Pharmacol., 55, 437-451.

3) Nagaya, H., Satoh, H. and Maki, Y. (1990) Possible mechanism for the inhibition of acid formation by proton pump inhibitor AG-1749 in isolated canine parietal cells. J. Pharmacol. Exp. Ther., 252, 12891295.

4) Holzer, P. (1998) Neural emergency system in the stomach. Gastroenterology, 114, 823-839.

5) Aoki, I. and Yashiki, T. (1991) High-performance liquid chromatographic determination of lansoprazole and its metabolites in human serum and urine. J. Chromatogr., 571, 283-290.

6) Takeyama, M., Matsuo, H. and Mori, K. (1993) Enzyme immunoassay of gastrin in human plasma. Chem. Pharm. Bull., 41, 2197-2199.

7) Takeyama, M., Yanaga, N., Yarimizu, K., Ono, J., Takaki, R., Fujii, N. and Yajima, H. (1990) Enzyme immunoassay of somatostatin (SS)-like immunoreactive substance in bovine milk. Chem. Pharm. Bull., 38, 456-459.

8) Naito, T., Itoh, H. and Takeyama, M. (2002) Hangeshashin-to raises levels of somatostatin, motilin and gastrin in the plasma of healthy subjects. Biol. Pharm. Bull., 25, 327-331.

9) Takeyama, M., Wakayama, K., Takayama, F., Kondo, K., Fujii, N. and Yajima, H. (1990) Microenzyme immunoassay of vasoactive intestinal polypeptide (VIP)-like immunoreactive substance in bovine milk. Chem. Pharm. Bull., 38, 960-962.

10) Nagano, T., Ikawa, K. and Takeyama, M. (1998) Enzyme immunoassay of calcitonin gene-related peptide-like immunoreactive substance in human plasma and saliva. Jpn. J. Hosp. Pharm., 24, 363369.

11) Takeyama, M., Mori, K., Takayama, F., Kondo, K., Kitagawa, K. and Fujii, N. (1990) Enzyme immunoassay of a substance P-like immunoreactive substance in human plasma and saliva. Chem. Pharm. Bull., 38, 3494-3496.

12) Kitagawa, T., Shimozono, T., Aikawa, T., Yoshida, T. and Nishimura, H. (1981) Preparation and characterization of hetero-bifunctional cross-linking reagents for protein modifications. Chem. Pharm. Bull., 29, 1130-1135. 
13) Ling, N., Burgus, R., Rivier, J., Vale, W. and Brazeau, P. (1973) The use of mass spectrometry in deducing the sequence of somatostatin - a hypothalamic polypeptide that inhibits the secretion of grouwth hormone. Biochem. Biophys. Res. Commun., 50, 127-133.

14) Schrumpf, E. (1978) The inhibitory action of somatostatin on the stomach. Adv. Exp. Med. Biol., 106, 235-240.

15) Szelenyi, I. (1980) Cholinergic components in the gastrin pathway of gastric acid stimulation. Experientia, 36, 973-974.

16) Vale, W., Rivier, C. and Brown, M. (1977) Regulatory peptides of the hypothalamus. Annu. Rev. Physiol., 39, 473-527.

17) Brown, J. C. and Parkes, C. O. (1967) Effect on fundic pouch motor activity of stimulatory and inhibitory fractions separated from pancreozymin. Gastroenterology, 53, 731-736.

18) You, C. H., Chey, W. Y. and Lee, K. Y. (1980) Studies on plasma motilin concentration and interdigestive motility of the duodenum in humans. Gastroenterology, 79, 62-66.

19) Itoh, Z., Honda, R., Hiwatashi, K., Takeuchi, S., Aizawa, I., Takayanagi, R. and Couch, E. F. (1976) Motilin-induced mechanical activity in the canine alimentary tract. Scand. J. Gastroenterol. Suppl., 39, 93-110.

20) Fahrenkrug, J. (1993) Transmitter role of vasoactive intestinal peptide. Pharmacol. Toxicol., 72, 354 363.

21) Andersson, P. O., Bloom, S. R., Edwards, A. V., Jarhult, J. and Mellander, S. (1983) Neural vasodilator control in the rectum of the cat and its possible mediation by vasoactive intestinal polypeptide. $J$. Physiol., 344, 49-67.
22) Angel, F., Go, V. L., Schmalz, P. F. and Szurszewski, J. H. (1983) Vasoactive intestinal polypeptide: a putative transmitter in the canine gastric muscularis mucosa. J. Physiol., 341, 641-654.

23) Hellström, P. M., Söder, O. and Theodorsson, E. (1991) Occurrence, release, and effects of multiple tachykinins in cat colonic tissues and nerves. Gastroenterology, 100, 431-440.

24) Inada, I., Inatomi, N. and Satoh, H. (1992) Effect of lansoprazole (AG-1749) on duodenal bicarbonate secretion in anesthetized rats. Jpn. Pharmacol. Ther., 20, 4345-4350.

25) Tsuji, S., Sun, W., Tsuji, M., Kawai, N., Kimura, A., Kakiuchi, Y., Yasumaru, S., Komori, M., Murata, H., Sasaki, Y., Kawano, S. and Hori, M. (2002) Lansoprazole induces mucosal protection through gastrin receptor-dependent up-regulation of cyclooxygenase-2 in rats. J. Pharmacol. Exp. Ther., 303, 1301-1308.

26) Itoh, H., Naito, T. and Takeyama, M. (2002) Laftidine changes levels of somatostatin, calcitonin gene-related peptide and secretin in human plasma. Biol. Pharm. Bull., 25, 379-382.

27) Takeuchi, K., Kato, S., Takeeda, M., Ogawa, Y., Nakashima, M. and Matsumoto, M. (2003) Facilitation by endogenous prostaglandins of capsaicininduced gastric protection in rodents through EP2 and IP receptors. J. Pharmacol. Exp. Ther., 304, 1055-1062.

28) Murakami, I., Satoh, H., Asano, S. and Maeda, R. (1996) Role of capsaicin-sensitive sensory neurons and nitric oxide in the protective effect of lansoprazole, a proton pump inhibitor, on the gastric mucosa in rats. Jpn. J. Pharmacol., 72, 137147. 